\title{
Distortions, Endogenous Managerial Skills and Productivity Differences*
}

\author{
Dhritiman Bhattacharya, Nezih Guner, and Gustavo Ventura ${ }^{\dagger}$
}

September 28, 2012

\begin{abstract}
We develop a span-of-control model where managerial skills are endogenous and the outcome of investments over the life cycle of managers. We calibrate this model to U.S. plant-size data to quantify the effects of distortions that are correlated with the size of production units, and how these effects are amplified by managerial investments. We find a quantitatively important role for managerial investments. Distortions that consist of a tax rate of $20 \%$ on the top $50 \%$ managers reduce steady-state output by about $14.6 \%$ in our benchmark model. When skills are exogenous the reduction is about $9.2 \%$.
\end{abstract}

Key Words: Distortions, Size, Skill Investments, Productivity Differences.

JEL Classification: O40, E23.

\footnotetext{
${ }^{*}$ We thank the Associate Editor (Richard Rogerson), two anonymous referees and participants at the mini-conference "Misallocation and Productivity" at the SED meetings in Ghent. We also thank seminar participants at CREI-MOVE Workshop on Misallocation and TFP, Einaudi Institute for Economics and Finance, Federal Reserve Bank of Atlanta, VII REDg Workshop on Dynamic General Equilibrium Macroeconomics in Madrid, Tinbergen Institute, and Yale for their comments. Rodica Calmuc and Ezgi Kaya provided excellent research assistance. Guner acknowledges financial support from Spanish Ministry of Economy and Competitiveness, Grant ECO2011-28822. All errors are ours.

${ }^{\dagger}$ Bhattacharya, Promontory Financial Group (email: dbhattacharya@promontory.com); Guner, ICREAMOVE, Universitat Autonoma de Barcelona, Barcelona GSE (email: nezih.guner@movebarcelona.eu); Ventura, Department of Economics, Arizona State University, USA (email: Gustavo.Ventura@asu.edu).
} 


\section{Introduction}

Why are some countries so much richer than others? From development accounting exercises, the answer depends heavily on productivity differences across countries (Klenow and Rodriguez-Clare, 1997; Prescott 1998; Hall and Jones, 1999; Caselli, 2005). Consequently, much work in the last decade or so has been devoted to understanding the determinants of these measured productivity differences. As part of this effort, a growing body of recent literature has studied the consequences of distortions that alter the efficient allocation of resources across production units, and show the extent to which these distortions can have substantial effects on aggregate productivity. ${ }^{1}$

A unifying feature of this literature is the assumption that the distribution of productivity across production units is exogenous, and invariant with respect to distortions. We depart from this practice in this paper, and work instead on the premise that such productivity levels are connected with purposeful investments from either firms, establishments or managers. In these circumstances, if the relevant decision unit expects higher tax rates (distortions) when productivity is high, investments in the enhancement of productivity will be affected. This behavior at the micro level will translate into a different distribution of productivity across production units in the long run. This distribution will feature a higher mass at relatively low values of productivity.

In this paper we investigate one channel that makes the intuition above operational. We develop a model where productivity across establishments is endogenous and driven by investments in managerial quality. We use this model to quantify the effects of distortions that grow with the size or productivity of production units (correlated distortions), and the extent to which these effects are magnified by managerial investments.

We study a span-of-control model with a life-cycle structure. Every period, a large number of finitely lived agents are born. These agents are heterogeneous in terms of their initial endowment of managerial skills. The objective of each agent is to maximize the lifetime utility from consumption. In the first period of their lives, agents make an irreversible decision to be either workers or managers. If an agent chooses to be a worker, her managerial

\footnotetext{
${ }^{1}$ See Bartelsman, Haltiwanger and Scarpetta (2012), Barseghyan and DiCecio (2011), Buera, Kabowski and Shin (2011), Caselli and Gennaioli (2012), D'Erasmo and Moscoso-Boedo (2012), Guner, Ventura and Xu (2008), Hsieh and Klenow (2009), Midrigan and Xu (2010), Restuccia and Rogerson (2008), among others.
} 
skills are of no use and she earns the market wage in every period until retirement. If an agent chooses to be a manager, she can use her managerial skills to operate a plant by employing labor and capital to produce output and collect the net proceeds (after paying labor and capital) as managerial income. Moreover, managers invest resources in skill formation, and as a result managerial skills grow over the life cycle. This implies that a manager can grow the size of her production unit and managerial income by investing a part of her current income in skill formation each period. As managers age and accumulate managerial skills, the distribution of skills (and productivity of production units) evolves endogenously, and could be affected by distortions.

In the model, the evolution of managerial skills and hence plant size depends not only on initially endowed skills, but also on skill investment decisions. These investment decisions reflect the costs (resources that have to be spent rather than being consumed) and the benefits (the future awards associated to being endowed with better managerial skills). A central assumption in our model is that there are complementarities between skills and investments: managers born with high skills find it optimal to invest more in skills over their lifetime than managers born with low skills. This model property amplifies initial heterogeneity in skills, and leads to increasing dispersion with age in the size of production plants that managers can operate.

We subsequently introduce distortions in the model that mimic productivity or sizedependent policies in practice. Specifically, at the start of life, agents are assigned an output tax if their initial level of managerial productivity is sufficiently high. This results in distortions that are positively correlated with the productivity and size of production units in a straightforward way. In this context, distortions have broadly two effects. First, a standard reallocation effect, as the enactment of distortions implies that capital and labor services flow from distorted to undistorted production units. Second, a novel skill accumulation effect, as distortions affect the patterns of skill accumulation and thus, the overall distribution of managerial ability (which manifests itself in the distribution of plant level productivity). Since initial skills and investments are complementary in the production of new skills, distorted managers born with more skills are affected more severely than distorted managers born with lower skills. This is key: the right tail of the ability distribution is centrally important for aggregate output, and in the current setup it reflects the outcome of endogenous investments. Hence, distortions can have a large impact on the right tail of the ability distribution and 
thus on aggregate output. In this context, we ask: What are the quantitative implications of these distortions for output, productivity and the size of establishments? What is the role of managerial investments in amplifying the effects of distortions on resource allocation?

We calibrate the model to match macroeconomic statistics as well as cross sectional features of the U.S. plant data. We assume for these purposes that the U.S. economy is relatively free of the distortions that we focus on. We find that the model can capture central features of the U.S. plant size distribution, including the upper and lower tails. This is critical; on the one hand, the upper tail of the size distribution accounts for the bulk of the employment and output in the economy. On the other hand, the lower tail of the size distribution accounts for the bulk of the plants in the economy.

We consider a menu of distortions and evaluate their effects on output, plant size and notions of productivity. We consider different distortion levels on the top $50 \%$ and top $25 \%$ of managers by initial ability. Introducing an implicit tax rate of $20 \%$ on the top $50 \%$ of managers leads to a reduction in output of about $14.6 \%$ and output per establishment of about $54.8 \%$. The effects on Total Factor Productivity (TFP) amount to 7.5\%. Such distortions lead to a sizeable change in mean plant size and a drastic drop in the share of employment in large plants (100 workers or more). Mean size falls to nearly half of the benchmark value and the employment share of large plants drops from about $45.8 \%$ of the total in the undistorted benchmark to about $20.4 \%$ in the distorted case. We find that the amplifying effects of skill investments is substantial: in the absence of skill investments, the same structure of distortions generates a reduction in output of only $9.2 \%$ in the long run - about a $63 \%$ reduction from the benchmark case. Therefore, our findings indicate that assuming an exogenous distribution of productivities might lead to a substantial underestimation of the consequences of distortions that affect the allocation of resources across production units. Put differently, under exogenous productivity levels, larger distortions are needed in order to generate given effects on output and establishment size.

The paper is organized as follows. Section 2 presents the model, the modeling of distortions and discusses the model implications and connection with the literature. Section 3 discusses the calibration of the benchmark model. Section 4 presents the findings associated to the introduction of distortions. Section 5 provides a quantification of the amplifying effects of skill investments and the importance of endogenizing the productivity distribution. Finally, section 6 concludes. 


\section{Model}

Consider the following life-cycle version of the Lucas (1978) span-of-control model. Each period, an overlapping generation of heterogeneous agents are born into economy that lives for $J$ periods. The objective of each agent is to maximize the present value of lifetime utility from consumption

$$
\sum_{j=1}^{J} \beta^{j-1} \log \left(c_{j}\right),
$$

where $\beta \in(0,1)$ and $c_{j}$ is the consumption of an age- $j$ agent.

Each agent is born with an initial endowment of managerial ability. We denote managerial ability by $z$, and assume that initial (age-1) abilities are drawn from an exogenous distribution with cdf $F(z)$ and density $f(z)$ on $\left[0, z^{\max }\right]$. Until retirement age $J_{R}$, each agent is also endowed with one unit of time which she supplies inelastically as a manager or as a worker. In the very first period of their lives, agents must choose either to be workers or managers. This decision is irreversible. A worker inelastically supplies her endowed labor time to earn the market wage every period until retirement. The decision problem of a worker is to choose how much to consume and save every period.

A manager's problem, however, is more complicated. A manager has access to a technology to produce output, which requires managerial ability in conjunction with capital and labor services. Hence, given factor prices, she decides how much labor and capital to employ every period. In addition, in every period, a manager decides how much of her net income to allocate towards current consumption, savings and investments in improving her managerial skills.

We assume that each cohort is $1+n$ bigger than the previous one. The population structure is stationary so that age- $j$ agents are a fraction $\mu_{j}$ of the population at any point in time. The weights are normalized to add up to one, and obey the recursion, $\mu_{j+1}=\mu_{j} /(1+n)$.

Technology Each manager has access to a span-of-control technology. A plant comprises of a manager with ability $z$ along with labor and capital,

$$
y=z^{1-\gamma}\left(k^{\alpha} n^{1-\alpha}\right)^{\gamma}
$$


where $\gamma$ is the span-of-control parameter and $\alpha \gamma$ is the share of capital. ${ }^{2}$ Every manager can enhance her future skills by investing current income in skill accumulation. The law of motion for managerial skills is given by

$$
z^{\prime}=z+g(z, x)=z+z^{\theta_{1}} x^{\theta_{2}} \text { with } \theta_{2} \in(0,1)
$$

where $z^{\prime}$ is next period's ability and $x$ denotes investment in skill accumulation. The skill accumulation technology described above satisfies three important properties, of which the first two follow from the functional form and the last one is an assumption. First, the technology shows complementarities between current ability and investments in next period's ability; i.e. $g_{z x}>0$. Second, $g(z, 0)=0$. That is, investments are essential to increase the stock of managerial skills. Finally, there are diminishing returns to skill investments: $g_{x x}<0$.

\subsection{Decisions}

Consider a stationary environment with constant factor prices $R$ and $w$. Let $a$ denote assets that pay the risk-free rate of return $r=R-\delta$.

Managers We assume that agents (managers as well as workers) can lend or borrow at the interest rate $r$ as long as they do not die in debt. Since there are no borrowing constraints, factor demands and per-period profits of a manager only depend on her ability $z$ and factor prices, not her assets.

Managerial income for a manager with ability $z$ is given by

$$
\pi(z, r, w)=\max _{n, k}\left\{z^{1-\gamma}\left(k^{\alpha} n^{1-\alpha}\right)^{\gamma}-w n-(r+\delta) k\right\}
$$

Factor demands are given by

$$
k(z, r, w)=((1-\alpha) \gamma)^{\frac{1}{1-\gamma}}\left(\frac{\alpha}{1-\alpha}\right)^{\frac{1-\gamma(1-\alpha)}{1-\gamma}}\left(\frac{1}{r+\delta}\right)^{\frac{1-\gamma(1-\alpha)}{1-\gamma}}\left(\frac{1}{w}\right)^{\frac{\gamma(1-\alpha)}{1-\gamma}} z
$$

and

$$
n(z, r, w)=((1-\alpha) \gamma)^{\frac{1}{1-\gamma}}\left(\frac{\alpha}{1-\alpha}\right)^{\frac{\alpha \gamma}{1-\gamma}}\left(\frac{1}{r+\delta}\right)^{\frac{\alpha \gamma}{1-\gamma}}\left(\frac{1}{w}\right)^{\frac{1-\alpha \gamma}{1-\gamma}} z .
$$

\footnotetext{
${ }^{2}$ In referring to production units, we use the terms establishment and plant interchangeably.
} 
Substituting these into the profit function, one can show that profits (managerial income) are given by

$$
\pi(z, r, w)=\Omega\left(\frac{1}{r+\delta}\right)^{\frac{\alpha \gamma}{1-\gamma}}\left(\frac{1}{w}\right)^{\frac{\gamma(1-\alpha)}{1-\gamma}} z,
$$

where is $\Omega$ a constant equal to

$$
\Omega \equiv(1-\alpha)^{\frac{\gamma(1-\alpha)}{1-\gamma}} \alpha^{\frac{\gamma \alpha}{1-\gamma}}(1-\gamma)^{\frac{1}{1-\gamma}}
$$

Note that since profits are a linear function of managerial ability, $z$, the impact of additional skills on profits is independent of $z$, and a function only of parameters and prices.

The dynamic programming problem of a manager of age $j$ is then given by

$$
V_{j}(z, a)=\max _{x, a^{\prime}}\left\{\log (c)+\beta V_{j+1}\left(z^{\prime}, a^{\prime}\right)\right\}
$$

subject to

$$
\begin{gathered}
c+x+a^{\prime}=\pi(z, r, w)+(1+r) a \quad \forall 1 \leq j<J_{R}-1, \\
c+a^{\prime}=(1+r) a \quad \forall j \geq J_{R},
\end{gathered}
$$

and

$$
z^{\prime}=z+g(z, x) \quad \forall j<J_{R}-1
$$

with

$$
V_{J+1}(z, a)=\left\{\begin{array}{c}
0 \text { if } a \geq 0 \\
-\infty, \text { otherwise }
\end{array}\right.
$$

Given her state $(z, a)$, a $j$-periods old manager decides how much to save, $a^{\prime}$, and how much to invest to enhance her skills. Up to the retirement age $J_{R}$, a manager's income consists of her managerial profits and her assets, while after age $J_{R}$ her only source of income is from her assets.

The solution to the dynamic programming problem of a manager is characterized by two conditions. First, the solution for next-period assets, $a^{\prime}$, is characterized by the standard Euler equation for asset accumulation

$$
\frac{1}{c_{j}}=\beta(1+r) \frac{1}{c_{j+1}} .
$$


Second, the optimality condition for $x$ and (6) imply the following no-arbitrage condition for investing in physical capital and skills

$$
(1+r)=\pi_{z}(r, w) g_{x}\left(z, x_{j}\right) .
$$

The left-hand side of the above equation is next period's gain in income from one unit of current savings. The manager can also use this one unit as an investment in skill. Hence, the term $g_{x}\left(z, x_{j}\right)$ on the right-hand side stands for the additional skills available next period from an additional unit of investment in the current period. The term $\pi_{z}(r, w)$ is the additional profit generated from an additional unit of managerial skills. Therefore, the right-hand side is the gain in utility by the $j$-period old manager from investing one unit of the current consumption good in skill accumulation. To get a unique interior optimum $g_{x x}$ must be negative, as assumed earlier. This implies that the marginal benefit of investing in skill accumulation is monotonically decreasing in the level of skill investment while the marginal cost, given by $(1+r)$, is constant.

Figure 1 illustrates the optimal decision for skill investments $x$ at a given age $j$. As the figure illustrates, a higher level of current (age $j$ ) managerial ability leads to higher skill investments as a result of complementarities built into the production of new managerial skills. Since this occurs at all ages, given prices, initial heterogeneity in skills is magnified by investments in skill acquisition.

The manager's problem generates decision rules for savings $a^{\prime}=a_{j}^{m}(z, a)$, investment in managerial skills, $x=x_{j}(z, a)$, as well as the associated factor demands given by $k=$ $k(z, r, w)$ and $n=n(z, r, w)$.

Workers The problem of an age- $j$ worker is simpler and is given by

$$
W_{j}(a)=\max _{a^{\prime}}\left\{\log (c)+\beta W_{j+1}\left(a^{\prime}\right)\right\}
$$

subject to

$$
c+a^{\prime}=w+(1+r) a \quad \forall 1 \leq j<J_{R}-1
$$

and

$$
c+a^{\prime}=(1+r) a \quad \forall j \geq J_{R},
$$


with

$$
W_{J+1}(a)=\left\{\begin{array}{c}
0 \text { if } a \geq 0 \\
-\infty, \text { otherwise }
\end{array} .\right.
$$

Let the associated savings decision of a worker be $a^{\prime}=a_{j}^{w}(a)$. Like managers, workers can borrow and lend without any constraint as long as they do not die with negative assets.

The objective of each agent born every period is to maximize lifetime utility by choosing to be a worker or a manager. Let $z^{*}$ be the ability level at which a 1-year old agent is indifferent between being a manager and a worker. This threshold level of $z$ is given by (as agents are born with no assets)

$$
V_{1}\left(z^{*}, 0\right)=W_{1}(0)
$$

Given all the assumptions made, $V_{1}$ is a continuous and a strictly increasing function of $z$. Therefore, (10) has a well-defined solution, $z^{*}$. Figure 2 depicts the solution.

\subsection{Equilibrium}

As we mentioned above, members of each new generation are endowed with managerial ability levels distributed with $\operatorname{cdf} F(z)$ and density $f(z)$ on $\left[0, z^{\max }\right]$. After the age- 1 , the distribution of managerial abilities is endogenous since it depends on investment decisions of managers over their life-cycle.

Let managerial abilities take values in set $\mathcal{Z}=\left[z^{*}, \bar{z}\right]$ with the endogenous upper bound $\bar{z}$. Similarly, let $\mathcal{A}=[0, \bar{a}]$ denote the possible asset levels. Let $\psi_{j}(a, z)$ be the mass of age- $j$ agents with assets $a$ and skill level $z$. Given $\psi_{j}(a, z)$, let

$$
\widetilde{f}_{j}(z)=\int \psi_{j}(a, z) d a
$$

be the skill distribution for age- $j$ agents. Note that $\widetilde{f}_{1}(z)=f(z)$ by construction.

Each period those agents whose ability is above $z^{*}$ work as managers, whereas the rest are workers. Then, in a stationary equilibrium with given prices, $(r, w)$, labor, capital and goods markets must clear. The labor market equilibrium condition can be written as

$$
\sum_{j=1}^{J_{R}-1} \mu_{j} \int_{z^{*}}^{\bar{z}} n(z, r, w) \widetilde{f}_{j}(z) d z=F\left(z^{*}\right) \sum_{j=1}^{J_{R}-1} \mu_{j}
$$

where $\mu_{j}$ is the total mass of cohort $j$. The left-hand side is the labor demand from $J_{R}-1$ different cohorts of managers. A manager with ability level $z$ demands $n(z, r, w)$ units of 
labor and there are $\tilde{f}_{j}(z)$ of these agents. The right-hand side is the fraction of each cohort employed as workers times the total mass of all non-retired cohorts in the economy.

In the capital market, the demand for capital services must equal the aggregate value of the capital stock. Hence,

$$
\sum_{j=1}^{J_{R}-1} \mu_{j} \int_{z^{*}}^{\bar{z}} k(z, r, w) \widetilde{f}_{j}(z) d z=K
$$

where $K$ is the aggregate stock of capital and $k(z, r, w)$ is capital demand from a manager with ability $z$. The goods market equilibrium condition requires that the sum of undepreciated capital stock and aggregate output produced in all plants in the economy is equal to the sum of aggregate consumption and savings across all cohorts plus skill investments by all managers across all cohorts.

\subsection{Distortions}

Consider now the environment in which managers face distortions to operate production plants. We model these distortions as output taxes that are dependent on the initial ability level of the manager.

Specifically, we select a level of initial managerial ability, $\widehat{z}$, so that managers with initial ability above this level face a common output tax $\tau \in(0,1)$. Once a manager is attached to a particular tax (distortion) $\tau$, this tax remains constant over her life cycle, and she obtains managerial rents $\pi(z, r, w, \tau)$ that obey

$$
\pi(z, r, w, \tau) \equiv \max _{n, k}\left\{(1-\tau) z^{1-\gamma}\left(k^{\alpha} n^{1-\alpha}\right)^{\gamma}-w n-(r+\delta) k\right\}
$$

With distortions the timing of events is as follows: (i) agents are born with managerial skills $z$; (ii) a distortion $\tau$ is assigned if $z \geq \widehat{z}$; (iii) occupational choice and decisions take place.

We note that our formulation delivers plant-specific, correlated distortions in a very simple and tractable way. If initial $z$ is sufficiently low, a potential manager does not face any distortion. If initial $z$ is sufficiently high, a potential manager faces an output $\operatorname{tax} \tau$.

Our formulation implies that production taxes distort the choice of capital and labor hired, and thus reduce optimal size measured in either capital or labor used, but leave the 
capital-labor ratio unaltered. Since distortions affect managerial rents, they matter for skill accumulation. The condition for skill accumulation is now given by

$$
(1+r)=\pi_{z}(r, w, \tau) g_{x}\left(z_{j}, x_{j}\right)
$$

As managerial rents are decreasing in $\tau$, the marginal benefit from skill investment declines as $\tau$ increases. Therefore, all the same, higher levels of distortions lead to lower levels of managerial skills, and due to complementarities between skills and the investments, the effect is larger for more skilled managers.

In our quantitative experiments, we assume that the taxes collected from managers are simply wasted. For comparison, we also report the key features of the model economy when the tax revenue is distributed proportionally to all workers and managers as an income subsidy.

\subsection{Discussion}

It is important at this point to comment on different aspects of our model, the underlying assumptions and its implications. We start by commenting on the nature of the distortions that we entertain, and their effects on the type of skill investments that we consider.

There are essentially two different ways to model distortions that are correlated with the size or productivity of production units: either as embodied in firms or establishments, or attached to individuals - managers- as we do in this paper. ${ }^{3}$ Both possibilities can be important channels for changes in the distribution of productivity across production units and their size, so our focus on the latter channel is by no means exhaustive. Our focus on distortions as attached to individuals has implications not only for the size of plants and their productivity, but also for the dynamics of managerial compensation as we elaborate later. As we model the acquisition of general managerial skills, our modeling of distortions captures the effects of distortions that affect the acquisition of such skills; our framework does not capture the effects of distortions that have consequences on investments in firm or plantspecific productivity. ${ }^{4}$ Our formulation roughly captures, for instance, the role of political

\footnotetext{
${ }^{3}$ In terms of modeling choices, these two ways can be mapped into the two canonical models of plant or firm heterogeneity: Lucas' (1978) span-of-control model and Hopenhayn's (1992) industry-dynamics model.

${ }^{4}$ There is a growing literature that emphasizes the importance of managerial inputs for firm's productivity; see Bloom and Van Reenen (2010). See also Burstein and Monge (2009) for the importance of international reallocation managerial know-how in income and welfare differences across countries.
} 
connections (or lack thereof) that are tied to individuals and that are potentially transferable across production units. ${ }^{5}$ Hence, our formulation does not capture the consequences of distortions on firm-specific investments in brand development, $\mathrm{R} \& \mathrm{D}$ or in the formation of firm-specific types of manager's or worker's skills.

More broadly, our formulation is a simple way to capture the effects of size-dependent policies that would tax a firm or plant's output (or input use) beyond a certain level. Such size-dependent policies would reduce the incentives of more productive managers to invest in their skills and grow, as the enhancement of their skills would increase the possibility that they would be subject to a higher tax rate. In the current setup, this is achieved by making distortions dependent on the initial skills of managers together with the fact that more skilled agents are more strongly affected by distortions.

Overall, our modeling of distortions and their effects on managerial skill investments captures a subset of the multiple effects that size or productivity-dependent distortions can have on productivity distributions. It should be viewed as a first step towards the understanding of the effects of such distortions in the determination of productivity distributions.

Amplification and Heterogeneity It is important to emphasize that distortions as modeled here have consequences for skill investments, size and the overall productivity distribution as goods are required in the technology to augment skills. This implies that the effects of changes in those variables are amplified by skill investments. ${ }^{6}$ These results connect our paper to the recent development and trade literature that considers amplification effects of productivity differences or distortions due to investments in skills and R\&D. Examples of these papers are Manuelli and Seshadri (2010), Erosa, Koreshkova and Restuccia (2010),

\footnotetext{
${ }^{5}$ There is a large literature that studies the value of political connections for firms. Focusing on Malaysia, Fisman (2001) and Johnson and Mitten (2003) argue that a large part of several firms' market value comes from their political connections. In a study more directly related to misallocation of resources, Khandelwal, Schott and Wei (2011) show that the way in which the Chinese government allocated export quotas for textiles under the Multi-fiber Arrangement, prior to the entry of China into WTO, implied substantial resource misallocation, as the firms that received the quotas were not necessarily the most productive ones. Ranasinghe (2012a) studies how the lack of property right and resulting possibility of extortion can affect agents' incentives to engage in managerial activity.

${ }^{6}$ The amplification effect depends critically on our assumption that skill investments are in terms of goods. In general, investments could be modeled as requiring either a time cost (i.e. forgone income), or a cost in terms of goods. We do not provide evidence on the relative importance of these alternatives, and focus only in the case of investments in terms of goods. Future work should investigate this issue for managerial investments in detail.
} 
Rubini (2011), Atkeson and Burstein (2010, 2011), Cubas, Ravikumar and Ventura (2012) and Gabler and Poschke (2012), among several others. The paper by Gabler and Poschke (2012) is in particular related to our paper, as they model costly experimentation as a determinant of firm-level productivity and aggregate productivity growth. These authors show that size-dependent policies can have harmful and severe effects on growth, as such policies reduce the incentives for firms to experiment and become more productive. ${ }^{7}$

The amplification effects of skill investments within our model depend critically on two parameters: $\theta_{1}$ and $\theta_{2}$. This can easily be seen in a simple version of the model with two periods and distortions. Given prices, the decision rule for managerial skill investments in the first period amounts to

$$
x^{*}=\Delta \theta_{2}^{\frac{1}{1-\theta_{2}}} z_{1}^{\frac{\theta_{1}}{1-\theta_{2}}}(1-\tau)^{\frac{1}{(1-\gamma)\left(1-\theta_{2}\right)}},
$$

where $\Delta$ is a constant depending on prices and model parameters. This implies that the growth rate of managerial skills is given by

$$
\frac{z_{2}^{*}}{z_{1}}=1+\Delta^{\theta_{2}} \theta_{2}^{\frac{\theta_{2}}{1-\theta_{2}}} z_{1}^{\frac{\theta_{1}+\theta_{2}-1}{1-\theta_{2}}}(1-\tau)^{\frac{\theta_{2}}{(1-\gamma)\left(1-\theta_{2}\right)}}
$$

The above expression has several implications. First, $x^{*} \rightarrow 0$ if $\theta_{2} \rightarrow 0$. In this limiting case, the distribution of productivities is exogenous (given by the initial distribution) and distortions have only allocative effects, as they do not change the distribution of managerial ability across managers (i.e. $z_{2}=z_{1}$ ). Second, $\theta_{1}=0$ reflects the absence of complementarities in skill production: conditional on $\tau$, all individuals invest the same amount regardless of their initial managerial ability. Third, skill investments amplify initial heterogeneity in skills if $\theta_{1}+\theta_{2}>1$. Thus, $\theta_{1}$ is important as in conjunction with $\theta_{2}$ it determines whether higher initial ability individuals are expected to display higher growth rates in skills (and incomes) than low ability ones. If $\theta_{1}+\theta_{2}=1$, given $\tau$, the growth rate in ability is the same for all

\footnotetext{
${ }^{7}$ The mechanism that we emphasize in the paper is connected to the recent work on the effects of correlated distortions by Restuccia (2011), Bello, Blyde and Restuccia (2012) and Ranasinghe (2012b). Bello, Blyde and Restuccia (2012) and Restuccia (2011), using an industry-dynamics model, allow establishments to invest resources to obtain a higher productivity upon entry. In their set-up, distortions also affect the distribution of productivity by making the returns from such investments lower. Ranasinghe (2012b) also studies an industry-dynamics model in which establishments invest in R\&D. Correlated distortions reduce the incentives to invest resources in R\&D and affect the productivity distribution. In a different context, Guvenen, Kuruscu and Ozkan (2011) study the effects of progressive taxation on the incentives to accumulate human capital and the implications for cross-country differences in earnings inequality.
} 
agents regardless of their initial productivity. ${ }^{8}$ Finally, the previous point implies that given $\theta_{2}$, the parameter $\theta_{1}$ might be key in accounting for the importance of large establishments in the data. Changes in this parameter amplify initial heterogeneity in skills, and thus, help concentrate labor and capital at larger plants.

\section{Parameter Values}

We assume the U.S. economy to be distortion free and calibrate the benchmark model parameters to match central aggregate and cross sectional features of the U.S. plant data. Before discussing the calibration strategy, it is worthwhile to emphasize important features of the U.S. plant size data collected from the 2004 U.S. Economic Census. The average size of a plant in the U.S. was about 17.9. The distribution of employment across plants is quite skewed; $72.5 \%$ of plants in the economy employed less than 10 workers, but accounted for only $15 \%$ of the total employment. On the other hand, less than $2.7 \%$ of plants employed more than 100 employees but accounted for about $46 \%$ of total employment. ${ }^{9}$ These are key features of the data for our analysis of distortions that are correlated with the size of production units.

We assume that the exogenous skill distribution of newborn agents, $z_{1}$, follows a log normal distribution. Specifically, we assume that $\log \left(z_{1}\right)$ is normally distributed with parameters $\mu_{z}$ and $\sigma_{z}$. We let the model period correspond to 10 years. Each cohort of agents enter the model at age 20 and live until they are 80 years old. Agents retire at age 60 . Hence, in the model agents live for 6 model periods; 4 as workers or managers and 2 as retirees. There is a total of 9 parameters to calibrate, as listed in Table 1. The product of two of these parameters, importance of capital $(\alpha)$ and returns to scale $(\gamma)$, determine the share of capital in output. We determine the values of capital share in output and the depreciation rate from the data. A measure of capital consistent with the current model on business plants should include capital accounted for by the business sector. Similarly a measure of output consistent with our definition of capital should only include output accounted for by the business sector. The measure of capital and output discussed in Guner et al (2008) is

\footnotetext{
${ }^{8}$ This property resembles the role of learning ability, and its interplay with initial human capital, in accounting for differential growth rates in earnings and the patterns of earnings dispersion over the life cycle. See Huggett, Ventura and Yaron $(2006,2011)$ and Guvenen and Kuruscu (2009), among others.

${ }^{9}$ The sample covers all private establishments in the U.S. in all sectors. Establishments are included in the sample if they have at least one employee.
} 
consistent with the current plant size distribution model. Hence we use the value of capital output ratio and the capital share reported in that paper. These values are 2.325 (at the annual level) and 0.317 , respectively, with a corresponding investment to output ratio of about 0.178. We choose the population growth rate in the model such that the annual population growth rate is $1.1 \%$. Given a capital output ratio and an investment ratio, our (stationary) law of motion of capital implies a depreciation rate of about $6.7 \%$ at the annual level.

After calibrating the depreciation rate and the population growth rate, we have 7 more parameters to calibrate: importance of capital, the parameter governing returns to scale, the discount factor, two parameters of the skill accumulation technology and the mean and variance of the skill distribution. Note that the capital share in the model is given by $\gamma \alpha$, and since this value has to be equal to 0.317 , a calibrated value for $\gamma$ determines $\alpha$ as well. Hence we have indeed 6 parameters to determine: $\gamma, \beta, \theta_{1}, \theta_{2}, \mu_{z}$ and $\sigma_{z}$. The resulting parameter values are displayed in Table 1.

At the aggregate level, we want the benchmark model to replicate the capital output ratio in the U.S. economy. At the cross sectional level, the model implied distribution of plants should capture some of the important features of the U.S. plant size distribution discussed in the beginning of this section. We normalize the mean of the skill distribution to zero and jointly calibrate the 5 remaining parameters to match the following 5 moments: mean plant size, fraction of plants with less than 10 workers, fraction of plants with more than 100 workers, fraction of the labor force employed in plants with 100 or more employees, and the aggregate capital output ratio. ${ }^{10}$ These moments together with their model counterparts are given in Table 2.

The benchmark model is successful in replicating multiple features of the U.S. plant size distribution. The coefficient of variation of the plant size distribution implied by the skill accumulation model is 3.32 which is close to the corresponding value (3.98) in the data. Indeed, the model is able to replicate properties of the entire plant size distribution fairly well as illustrated in Figures 3 and 4. The success of the model in accounting for the tail of the plant-size distribution is important; as we argued earlier, the bulk of employment is there.

\footnotetext{
${ }^{10} \mathrm{We}$ approximate the initial distribution of managerial skills using gridpoints that range from $-3 \sigma_{z}$ and $3 \sigma_{z}$.
} 
Skill Investments In our calibration, the fraction of resources that are invested in skill accumulation is about $2.5 \%$ of GDP in the benchmark economy. Despite the relatively small fraction of resources devoted to the improvement of managerial skills, the incomes of managers grow significantly with age. In the model economy, a manager who is in her 40s (age 3) earns about 2.7 times as much as a manager who is in her 20s (age 1). How does this compare to U.S. data? To answer this question, we first have to take a stand on who is a manager and who is a worker in the data. On one extreme, one can consider 'chief executives', which amount to about $0.9 \%$ of the labor force in 2000 . A more comprehensive definition can include all those individuals who are categorized in executive, administrative or managerial occupations. ${ }^{11}$ This group amounts to about $9.2 \%$ of the labor force in 2000 . About $5.3 \%$ of the workforce are managers in the model, which is right in the middle of these two estimates.

In order to calculate the growth rate of managerial incomes over the life-cycle, we use the broader definition of managers above. In an attempt to control for cohort effects, we use the 1980 U.S. Census to construct real managerial incomes for ages 20-29, the 1990 Census for ages 30-39, and the 2000 Census for ages 40-49. ${ }^{12}$ The income measure is the total personal income deflated by the Consumer Price Index (CPI). This procedure reveals that managers' incomes indeed grow significantly with age, as they grow by a factor of about 2.8 , from ages 20-29 to ages 40-49. Alternatively, if we normalize managerial incomes by the aggregate level of labor income in each year in Census data, we obtain a growth factor of about 2.2. If instead we control for potential factors affecting all managers as a group, by normalizing managerial incomes by the overall level of managerial incomes (across all ages) in a given year, we obtain a growth factor is of about 2.1. Our model, estimated exclusively with

\footnotetext{
${ }^{11}$ We used the 1990 Occupational Classification Code (OCC) with occupation codes 4 to 22 counted as managers in the U.S. Census. The set of occupations that are classified as managers include chief executives and public administrators, financial managers, human resources and labor relations managers, managers and specialists in marketing and advertising and public relations, managers in education and related fields, managers of medicine and health occupations, postmasters and mail superintendents, managers of food-serving and lodging establishments, managers of properties and real estate, and funeral directors, managers of service organizations and managers and administrators.

${ }^{12}$ The key advantage of the Census data is its size, that allows us to construct life-cycle profiles for narrowly defined occupations. This would not be possible using the Panel Study of Income Studies (PSID), which despite its obvious advantage of tracking individuals, has much fewer observations. Income data is top coded in the Census. The limit was $\$ 1,000,000$ in 2000 .
} 
plant-level data, produces an estimate in the range implied by the Census income data. ${ }^{13}$

\section{Results}

In this section, we present and discuss the central quantitative findings of the paper.

\subsection{Effects of Distortions}

We evaluate the effects of distortions in two alternative cases. In the first one, distortions are imposed on the top $50 \%$ of managers by initial managerial ability in the benchmark economy. In the second case, distortions are imposed on the top $25 \%$ of managers by initial productivity. These considerations dictate the value of the threshold $\widehat{z}$.

Table 3 and 4 show the main findings for values of output tax rates equal to $10 \%$ and $20 \%$. Figure 5 shows the implications for a wider range of tax distortions for output and mean size. As Table 3 demonstrates, output tax distortions of $20 \%$ on the top $50 \%$ of managers lead to a reduction in aggregate output of about $14.6 \%$, and to a substantial increase in the number of production establishments of nearly $90 \% .{ }^{14}$ Mean size falls from the benchmark value of 17.7 employees to about 8.9 employees. As a result of these changes, output per establishment drops by much more than the reduction in aggregate output: $54.8 \%$. This occurs as with the introduction of output taxes, relatively large, distorted establishments reduce their demand for capital and labor services, leading to a reduction in the wage rate across steady states. This prompts the emergence of smaller production units, as individuals with low initial managerial ability become managers.

An important aspect of the results in Tables 3 and 4 concerns the behavior of Total Factor Productivity (TFP). We measure TFP as an empirical researcher would using data from our model, with capital and labor shares equal to $\alpha \gamma$ and $1-\alpha \gamma$, respectively. The results show that distortions have moderate consequences on TFP. This variable falls by about $3.0 \%$ and $7.5 \%$ under both $10 \%$ and $20 \%$ tax rates, respectively, when the top $50 \%$ of

\footnotetext{
${ }^{13}$ In related fashion, the data also shows that size grows over the life-cycle of plants. Hsieh and Klenow (2012), among others, document that U.S. manufacturing plants that are more than 40 years old are about 7 times larger than those that are less than 5 years old. These authors also show that the growth rate is much lower in Mexico, where older plants are about twice as large as the younger ones, and nearly absent in India. Our model is silent about these facts.

${ }^{14}$ Top $50 \%$ of managers from the benchmark economy constitute about $35 \%$ and $27 \%$ of all managers when $10 \%$ and $20 \%$ taxes are introduced, as the total number of managers increase with distortions.
} 
managers are subject to distortions. The moderate effects of distortions on TFP, relative to the larger effects on output, are not surprising. They are driven by the fact that distortions reduce the aggregate capital stock across steady states. That is, substantial reduction in output are partially compensated by reductions in capital in the computation of TFP.

The effects outlined above are also present in the analysis in Guner et al (2008), in the context of a standard span-of-control model with capital accumulation. In the current context with skill investments, the consequences of distortions that affect the size of production establishments are more severe. Distortions have detrimental consequences on skill investments, and on average, managers with higher initial ability are more severely distorted. This contributes to a substantial decline in average managerial ability, which declines by nearly $55 \%$ under $20 \%$ tax rates on the top $50 \%$ of managers.

Indeed, mean ability of managers declines due to two reasons. The first reason is a standard reallocation effect: distortions lead to a reallocation of resources across establishments that leads to lower demand for labor and lower wages and results in the emergence of smaller establishments. As managers of these establishments have initial skills that are below the cutoff level, they reduce average managerial skills. The second reason, a skill accumulation effect, is due to the forces that we highlight in this paper. Distorted individuals, who tend to be the initially most able ones, reduce their investments in managerial skills, leading in turn to a further reduction in the economy-wide level of managerial ability. Investment in managerial skills declines from $2.5 \%$ of output in the benchmark economy to about $1.5 \%$ under tax rates of $20 \%$ on the top $50 \%$ of managers. Both forces contribute to the decline in aggregate output, and the degree of reallocation of resources from large establishments to small ones. Indeed, as Table 3 shows, distortions lead to a substantial redistribution of production across establishments. A tax rate of $20 \%$ leads to a drop in the share of employment accounted for by large establishments (100 and more workers) from about $45.8 \%$ to $20.4 \%$ of total employment, and an increase in the share of small ones (less than 10 workers) from $17.8 \%$ to $42.7 \%$. Not surprisingly, the introduction of distortions leads to age-income profiles for managers that are flatter than in the benchmark economy. Between age 1 and age 3 , the income of a manager grows by a factor of 2.7 in the benchmark economy, while the growth factor is around 2 when the output tax rate amounts to $20 \%$. 
Skill Accumulation Effects It is worth discussing in more detail how the skill accumulation effects operate in the context of our model economy. Recall that there are two types of managers in the model with distortions; those who are distorted and those who are not, depending on their initial managerial ability. Figure 6 illustrates the differential effects on skill investments of different managers, by plotting age-1 skill investments in the benchmark economy and under a $20 \%$ tax rate as a function of initial skills.

The effect of distortions is larger for more skilled managers, as the figure demonstrates. Moreover, the figure shows that as initial skills increase, there is a threshold level of skills at which managerial work is more profitable than regular work and investments start. In line with our previous discussion, this threshold level falls with the introduction of distortions as new, small establishments emerge.

Finally, Figure 6 illustrates the presence of indirect effects on skills associated with the distortions across steady-state equilibria. Note that undistorted managers increase their skill investments when distortions are present in relation to the investments in the benchmark economy. Since the steady state with distortions features a lower wage rate than the benchmark economy, undistorted managers have stronger incentives to accumulate skills that (partially) moderate the negative effects on skill investments from distorted managers. Overall, the detrimental effects on the skill investments and lifetime managerial skills associated to the distortions are the dominant force. In section 5 , we quantify the importance of skill investments for output and other aggregates.

The Location of Distortions Do the aggregate effects of distortions depend critically on the level of initial skills at which they become operational? The question can be answered by comparing the effects of distortions in Tables 3 and 4, when they are applied to the top $50 \%$ versus the top $25 \%$ of managers by initial ability. A $20 \%$ tax rate reduces output per worker by about $14.6 \%$ when the top $50 \%$ managers are taxed, whereas the reduction amounts to $13.3 \%$ when the top $25 \%$ managers are taxed. Mean establishment size drops by about nearly $50 \%$ and $43.5 \%$, respectively. From these findings, it is clear that the differences between the cases are not of first-order importance. Taxing top 25\% of managers is less costly in terms of overall tax burden, as tax collection amounts to $9.5 \%$ of GDP while it is $12.9 \%$ of GDP when top $50 \%$ of managers are taxed. The aggregate consequences, however, are similar since the most able managers at birth are subject to the distortions in both cases 
and these managers account for the bulk of output, employment and skill investments in the benchmark economy. It follows that distortions on their behavior can be quite costly for aggregates.

The Importance of Distortions Correlated with Productivity The findings outlined above are connected with previous findings in the literature. Previous work has shown that for distortions to matter for aggregates and productivity, they have to be heavier for more productive establishments than for less productive ones (Guner et al (2008) and Restuccia and Rogerson (2008)). Does this result still hold in the current environment? Note that distortions as considered here, even if the same level of distortion applies to all managers, affect investment in skills and thus may matter.

To assess the importance of the connection between productivity and distortions in the current environment, we conduct the following experiment: we apply the average tax rates that are implied by our exercises to all managers. ${ }^{15}$ As we show in Tables 3 and 4, we find that the reductions in aggregate output are much smaller than in our benchmark, while leaving mean establishment size essentially unchanged. We conclude from this exercise that the positive association between size and distortions is a central force in the current environment as well.

Revenue Neutrality The quantitative experiments discussed above imply that the revenue collected from the introduction of distortions is not constant. To what extent are our findings driven by this feature? To answer this question, we introduce a flat-rate subsidy on either labor income or managerial income, applied to all individuals, so that the net amount of resources effectively extracted from the economy amounts to zero.

The bottom panel of Table 3 and 4 presents the findings for the case of output, TFP and mean size. The results show that the reported effects do not crucially depend on whether implicit tax collections are returned to individuals in a proportional way. The distorting effects from the distortions that we consider, not their income effects, are the dominant force in our findings.

\footnotetext{
${ }^{15}$ The average tax rates on managers are $3.6 \%$ and $5.4 \%$, respectively.
} 


\section{Amplification Effects: The Importance of Skill In- vestments}

In this section we quantify the importance of the mechanism that we highlight in the paper. We ask to what extent the effects on output, productivity and the size of plants depend on the presence of skill investments by managers.

For these purposes, we conduct experiments that isolate the importance of skill investments. We calculate stationary equilibria in the presence of distortions while keeping the decision rules for skill investments fixed from the benchmark (undistorted) economy for all individuals. By construction then, the distorted economies have the same levels of managerial productivity across individuals as the benchmark economy without distortions - except for who is a manager and who is not, that will change endogenously. As a result, effects from distortions are driven only by the consequences of distortions on managers' demand for capital and labor.

Findings The main findings of the experiments are summarized in Table 5 when the top $50 \%$ managers are subject to distortions. Figure 7 shows the output effects for multiple values of tax rates.

Table 5 shows that a $20 \%$ tax rate reduces output and mean size under fixed decision rules for skill investments by $9.2 \%$ and $43.5 \%$, respectively. The corresponding values when skills are endogenous are $14.6 \%$ and $49.8 \%$. The number of establishments increases by $69.8 \%$ under fixed decision rules, whereas it increases by about $88.8 \%$ when skills are endogenous. From these findings we conclude that the effects associated with the endogeneity of managerial skills are reflected primarily on output. The results indicate a significant degree of amplification stemming from the endogeneity of managerial skills: the model with fixed decision rules captures only about $63 \%$ of the output effects of a $20 \%$ tax rate. In different terms, larger distortions are needed to generate given output effects if skills are exogenous.

Note that the response of the employment share of large establishments critically depends on whether skills are endogenous or not. Table 5 shows that for a tax rate of $20 \%$, the model with exogenous skills captures only about $52 \%$ of the changes in the employment share at large establishments observed under endogenous skills. A similar result holds under a $10 \%$ tax rate. We conclude from these findings that the substantial amplification effects on output are 
driven primarily by the strong consequences of distortions on high ability managers. Given the complementarities on skill accumulation built into the model, distortions affect severely the lifetime skills of high-ability managers. This translates into the significant amplification effects on output that we uncover.

\section{Conclusion}

We developed a span-of-control model where managers invest in the quality of their skills, and used it to quantify the significance of distortions correlated with the size of production units. We found that these distortions can lead to substantial effects on output, productivity and the size distribution. These effects are non-trivially magnified by the endogeneity of managerial skills.

A central implication of our findings is that relatively small distortions can lead to substantial effects in the long run. As we elaborate in the text, the endogeneity of managerial skills is key for this result. We found that when managerial skills are exogenous, our model substantially underestimates the consequences of distortions on output and other aggregates. Overall, our results point to importance of considering models in future research where the distribution of productivities is endogenous and thus, affected by the structure of distortions.

We close the paper with three comments. First, our modeling of distortions is straightforward and aims to capture the key elements of distortions on resource allocation that depend on the size and/or productivity of establishments. But as we mentioned above, the model can be extended to accommodate the explicit modeling of size-dependent policies. Such a richer specification of distortionary policies would make the analysis more involved, but their effects will operate in a similar way: improvements in productivity move production units closer to distortions and hence, reduce the incentives for investing in such improvements.

Second, our modeling of managerial skills as endogenous and dependent on investments in goods, implies that changes in economy-wide productivity levels have effects on skill investment decisions and thus, on productivity and the size of establishments. As a result, the model has the potential to generate cross-country differences in size distribution of establishments based on the interplay between cross-country differences in aggregate productivity levels and distortions. We have not explored this topic in this paper, but it constitutes a natural extension of our analysis. 
The final comment pertains pertains to the model's implications for data on the life cycle of managers. We are unaware of empirical work that has focused at the life cycle of managers in detail. The discussion in section 3 indicates that our model is broadly consistent with the growth of managerial income over the life cycle, providing support for our parameterization. In any case, a deeper study that connects an occupational choice model with data on multiple aspects of the life cycle of managers seems warranted. We leave this and other extensions for future work. 


\section{References}

[1] Atkeson, Andrew and Ariel Burstein. 2011. "Aggregate Implications of Innovation Policy." mimeo.

[2] Atkeson, Andrew and Ariel Burstein. 2010. "Innovation, Firm dynamics, and International Trade". Journal of Political Economy, 118(3): 433-484.

[3] Barseghyan, Levon and Riccardo DiCecio. 2011. "Entry Costs, Industry Structure, and Cross-Country Income and TFP Differences." Journal of Economic Theory, 106(5): 1828-1851.

[4] Bartelsman, Eric, John Haltiwanger and Stefano Scarpetta. 2012. "Cross Country Differences in Productivity: The Role of Allocative Efficiency," forthcoming American Economic Review.

[5] Bello, Omar D., Blyde Juan S. and Diego Restuccia. 2012. "Venezuela's Growth Experience." Latin American Journal of Economics, 48 (2): 199-226

[6] Bloom, Nicholas and Van Reenen, John. 2010. "Why Do Management Practices Differ across Firms and Countries?" Journal of Economic Perspectives, 24(1): 203-224.

[7] Buera, Francisco J., Joseph P. Kaboski, and Yongseok Shin. 2011. "Finance and Development: A Tale of Two Sectors." American Economic Review, 101(5): 1964-2002.

[8] Burstein, Ariel and Alexander Monge-Naranjo. "Foreign know-how, Firm control, and the Income of developing countries. 2009. "Quarterly Journal of Economics, 124(1): 149-195.

[9] D’Erasmo, Pablo and Hernán Moscoso-Boedo. 2012. "Financial Structure, Informality and Development. "Journal of Monetary Economics, 59(3): 286-302.

[10] Caselli, Francesco. 2012. "Accounting for Cross-Country Income Differences," in Handbook of Economic Growth, ed. Philippe Aghion and Steven N. Durlauf, Amsterdam:Elsevier.

[11] Caselli, Francesco and Nicola Gennaioli. 2005. "Dynastic Management." London School of Economics, forthcoming Economic Inquiry. 
[12] Cubas, Germán, B. Ravikumar and Gustavo Ventura. 2011. "Talent, Labor Quality and Economic Development." mimeo.

[13] Erosa, Andrés, Tatyana Koreshkova and Diego Restuccia. 2010. "How Important is Human Capital? A Quantitative Theory Assessment of World Income Inequality," Review of Economic Studies, 77 (4): 1421-49.

[14] Fisman, Raymond. 2001. "Estimating the Value of Political Connections," American Economic Review, 91(4): 1095-1102.

[15] Gabler, Alain and Markus Poschke. 2012. "Growth through Experimentation." mimeo.

[16] Guner, Nezih, Gustavo Ventura and Yi Xu. 2008. "Macroeconomic Implications of SizeDependent Policies." Review of Economic Dynamics, 11(4): 721-744.

[17] Guvenen, Fatih and Burhanettin Kuruscu. 2009. "A Quantitative Analysis of the Evolution of the U.S. Wage Distribution: 1970-2000." NBER Macroeconomics Annual, 24: 231-276.

[18] Guvenen, Fatih, Kuruscu, Burhanettin and Serdar Ozkan. 2011. "Taxation of Human Capital and Wage Inequality: A Cross-Country Analysis." mimeo.

[19] Hall, Robert, and Charles Jones. 1999. "Why Do Some Countries Produce So Much More Output per Worker than Others?" Quarterly Journal of Economics, 114(1): 83116.

[20] Hsieh, Chang-Tai, and Peter Klenow. 2009. "Misallocation and Manufacturing TFP in China and India." Quarterly Journal of Economics, 124(40): 1403-1448.

[21] Hsieh, Chang-Tai and Peter Klenow. 2012. "The Life Cycle of Plants in India and Mexico," mimeo.

[22] Hopenhayn, Hugo A. 1992. "Entry, Exit, and firm Dynamics in Long Run Equilibrium." Econometrica , 60 (5): 1127-1150

[23] Huggett, Mark, Gustavo Ventura and Amir Yaron. 2006. "Human Capital and Earnings Distribution Dynamics." Journal of Monetary Economics, 53(2): 265-290. 
[24] Huggett, Mark, Gustavo Ventura and Amir Yaron. 2011. "Sources of Lifetime Inequality." American Economic Review, 101(7): 2923-54.

[25] Johnson, Simon and Mitton, Todd. 2003. "Cronyism and Capital Controls: Evidence from Malaysia." Journal of Financial Economics 67(2): 351-382.

[26] Khandelwal, Amit, Peter Schott and Shang-Jin Wei. 2011. "Trade Liberalization and Embedded Institutional Reform: Evidence from Chinese Exporters , " mimeo.

[27] Klenow, Peter and Andrés Rodriguez-Clare. 1997. "The Neoclassical Revival in Growth Economics: Has it Gone Too Far?" In Macroeconomics Annual 1997. , ed. Ben Bernanke and Julio Rotemberg, 73-102. Cambridge: MIT Press.

[28] Lucas, Jr., Robert E. 1978. "On the Size Distribution of Business Firms.” Bell Journal of Economics, 9(2): 508-523.

[29] Manuelli, Rodolfo and Ananth Seshadri. 2010. "Human Capital and the Wealth of Nations", mimeo.

[30] Midrigan, Virgiliu and Yi Xu. 2010. "Finance and Misallocation: Evidence from Plantlevel Data." mimeo.

[31] Prescott, Edward. 1998. "Needed: A Theory of Total Factor Productivity." International Economic Review, 39(3): 525-551.

[32] Ranasinghe, Ashantha. 2012a. "Property Rights, Extortion and the Misallocation of Talent." mimeo.

[33] Ranasinghe, Ashantha. 2012b. "Impact of Policy Distortions on Plant-level Innovation, Productivity Dynamics and TFP." mimeo.

[34] Restuccia, Diego. 2011. "The Latin American Development Problem." mimeo.

[35] Restuccia, Diego and Richard Rogerson. 2008. "Policy Distortions and Aggregate Productivity with Heterogeneous Establishments." Review of Economic Dynamics, 11(4): 707-720.

[36] Rubini, Loris. 2011. "Innovation and the Elasticity of Trade Volumes to Tariff Reductions." mimeo. 
Table 1: Parameter Values (annualized)

\begin{tabular}{lc}
\hline \hline Parameter & $\underline{\text { Value }}$ \\
Population Growth Rate $(n)$ & 0.011 \\
Depreciation Rate $(\delta)$ & 0.067 \\
\hline Importance of Capital $(\alpha)$ & 0.426 \\
Returns to Scale $(\gamma)$ & 0.765 \\
Mean Log-managerial Ability $\left(\mu_{z}\right)$ & 0 \\
Dispersion in Log-managerial Ability $\left(\sigma_{z}\right)$ & 2.285 \\
Discount Factor $(\beta)$ & 0.946 \\
Skill accumulation technology $\left(\theta_{1}\right)$ & 0.932 \\
Skill accumulation technology $\left(\theta_{2}\right)$ & 0.405 \\
\hline \hline
\end{tabular}

Table 2: Empirical Targets: Model and Data

\begin{tabular}{lcc}
\hline \hline Statistic & $\underline{\text { Data }}$ & Model \\
Mean Size & 17.9 & 17.7 \\
Capital Output Ratio & 2.325 & 2.332 \\
Fraction of Small (0-9 workers) establishments & 0.725 & 0.736 \\
Fraction of Large (100+ workers) establishments & 0.026 & 0.028 \\
Employment Share of Large establishments & 0.462 & 0.458 \\
\hline \hline
\end{tabular}


Table 3: Effects of Distortions -Top 50\% of Managers Taxed

\begin{tabular}{lccc}
\hline \hline Statistic & Benchmark & \multicolumn{2}{c}{ Tax Rate } \\
& & $10 \%$ & $20 \%$ \\
\hline Aggregate Output & 100 & 93.0 & 85.4 \\
TFP & 100 & 97.2 & 92.5 \\
Number of Establishments & 100 & 142.2 & 188.8 \\
Mean Size & 100 & 68.6 & 50.2 \\
Output per Establishment & 100 & 65.4 & 45.2 \\
Mean Ability & 100 & 65.8 & 45.1 \\
Investment in Skills (\% of GDP) & 2.5 & 1.95 & 1.46 \\
Employment Share (Small, \%) & 17.8 & 29.7 & 42.7 \\
Employment Share (Large, \%) & 45.8 & 34.9 & 20.4 \\
& & & \\
Revenue Neutrality & & & \\
Output & 100 & 96.4 & 90.1 \\
TFP & 100 & 99.0 & 95.2 \\
Mean Size & 100 & 72.0 & 51.1 \\
& & & \\
Uniform Distortions & & & \\
Output & 100 & 97.5 & 96.2 \\
TFP & 100 & 99.3 & 99.0 \\
Mean Size & 100 & 97.5 & 97.5 \\
\hline \hline
\end{tabular}

Note: Entries show the effects on displayed variables associated to the introduction of distortions.

The distortions are applied to the top 50\% of managers in the benchmark economy by initial ability. 'Small' stands for establishments with less than 10 workers whereas 'Large' stands for establishments with 100 workers or more. 
Table 4: Effects of Distortions -Top 25\% of Managers Taxed

\begin{tabular}{lccc}
\hline \hline Statistic & Benchmark & \multicolumn{2}{c}{ Tax Rate } \\
& & $10 \%$ & $20 \%$ \\
\hline Aggregate Output & 100 & 93.6 & 86.7 \\
TFP & 100 & 97.0 & 92.3 \\
Number of Establishments & 100 & 135.8 & 169.8 \\
Mean Size & 100 & 72.0 & 56.5 \\
Output per Establishment & 100 & 68.9 & 51.1 \\
Mean Ability & 100 & 68.3 & 49.4 \\
Investment in Skills (\% of GDP) & 2.5 & 1.94 & 1.52 \\
Employment Share (Small, \%) & 17.8 & 26.3 & 34.2 \\
Employment Share (Large, \%) & 45.8 & 30.9 & 11.3 \\
& & & \\
Revenue Neutrality & & & \\
Output & 100 & 96.3 & 90.1 \\
TFP & 100 & 98.5 & 94.2 \\
Mean Size & 100 & 73.8 & 57.9 \\
& & & \\
Uniform Distortions & & & \\
Output & 100 & 98.7 & 97.9 \\
TFP & 100 & 99.7 & 99.4 \\
Mean Size & 100 & 97.6 & 97.5 \\
\hline \hline
\end{tabular}

Note: Entries show the effects on displayed variables associated to the introduction of distortions.

The distortions are applied to the top $25 \%$ of managers in the benchmark economy by initial ability. 'Small' stands for establishments with less than 10 workers whereas 'Large' stands for establishments with 100 workers or more. 
Table 5: Importance of Skill Investments -Top 50\% of Managers Taxed

\begin{tabular}{|c|c|c|c|c|}
\hline \multirow[t]{2}{*}{ Statistic } & \multicolumn{2}{|c|}{$10 \%$ Tax Rate } & \multicolumn{2}{|c|}{$20 \%$ Tax Rate } \\
\hline & (endogenous) & (fixed) & (endogenous) & (fixed) \\
\hline Aggregate Output & 93.0 & 95.8 & 85.4 & 90.8 \\
\hline TFP & 97.2 & 99.7 & 92.5 & 98.2 \\
\hline Number of Establishments & 142.2 & 132.8 & 188.8 & 169.8 \\
\hline Mean Ability & 65.8 & 77.7 & 45.1 & 62.4 \\
\hline Mean Size & 68.6 & 73.8 & 50.2 & 56.5 \\
\hline Employment Share (Small, \%) & 29.7 & 26.9 & 42.7 & 37.7 \\
\hline Employment Share (Large, \%) & 34.9 & 40.3 & 20.4 & 32.7 \\
\hline
\end{tabular}

Note: Entries show the effects on displayed variables associated to the introduction of distortions in different cases, when distortions are imposed on the top $50 \%$ of managers by initial ability in the benchmark economy. The entries referring to 'endogenous' correspond to the calculations under the model with skill accumulation by managers considered in this paper. The entries referring to 'fixed' correspond to the calculations under the fixed decision rules for skill investments from the benchmark economy, as explained in the text. 'Small' stands for establishments with less than 10 workers whereas 'Large' stands for establishments with 100 workers or more. 
Figure 1. Determination of Skill Investment

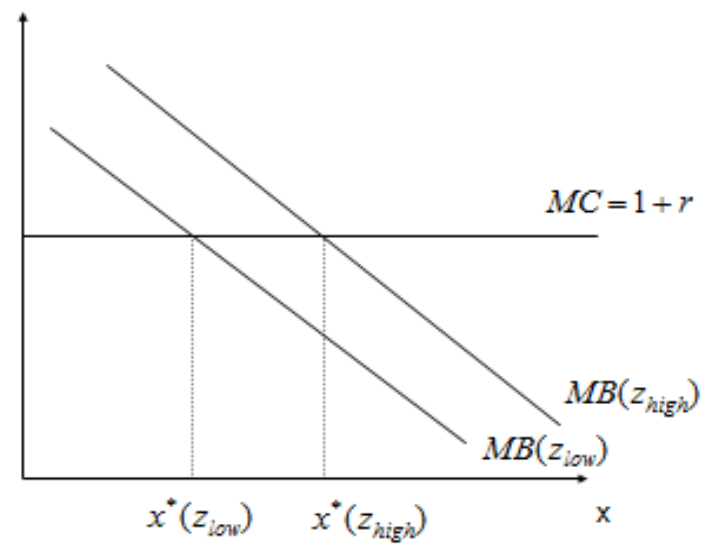

Figure 2. Occupational Choice

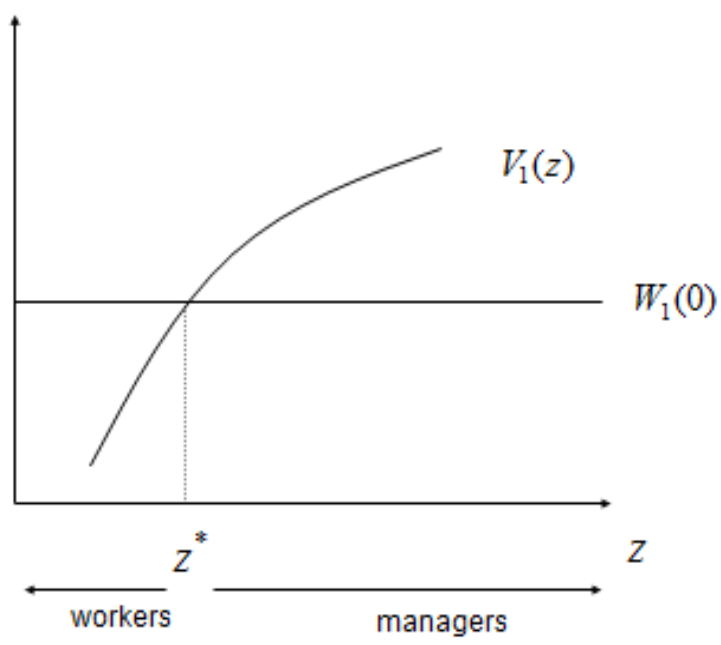


Figure 3. Size Distribution

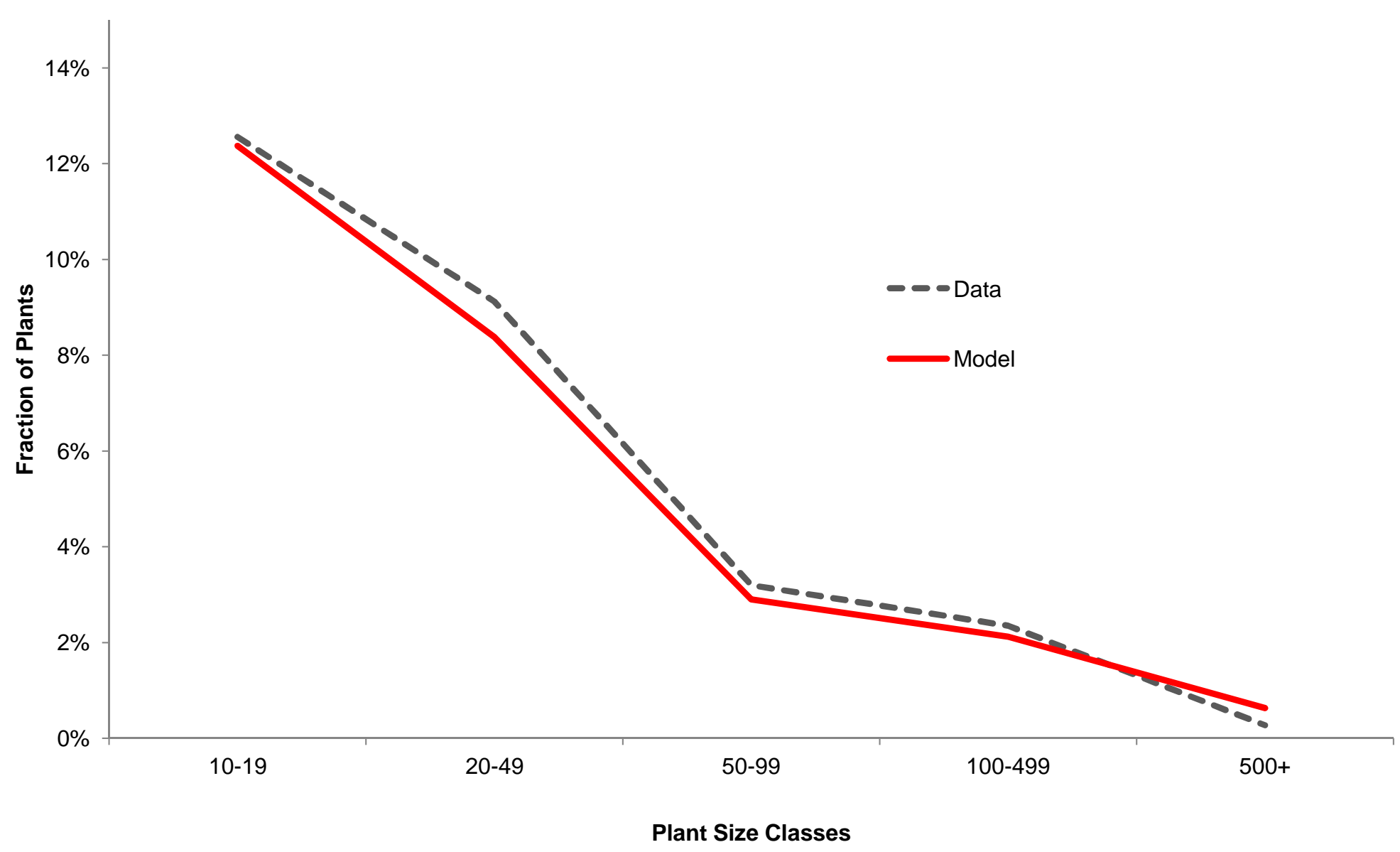


Figure 4. Employment Shares

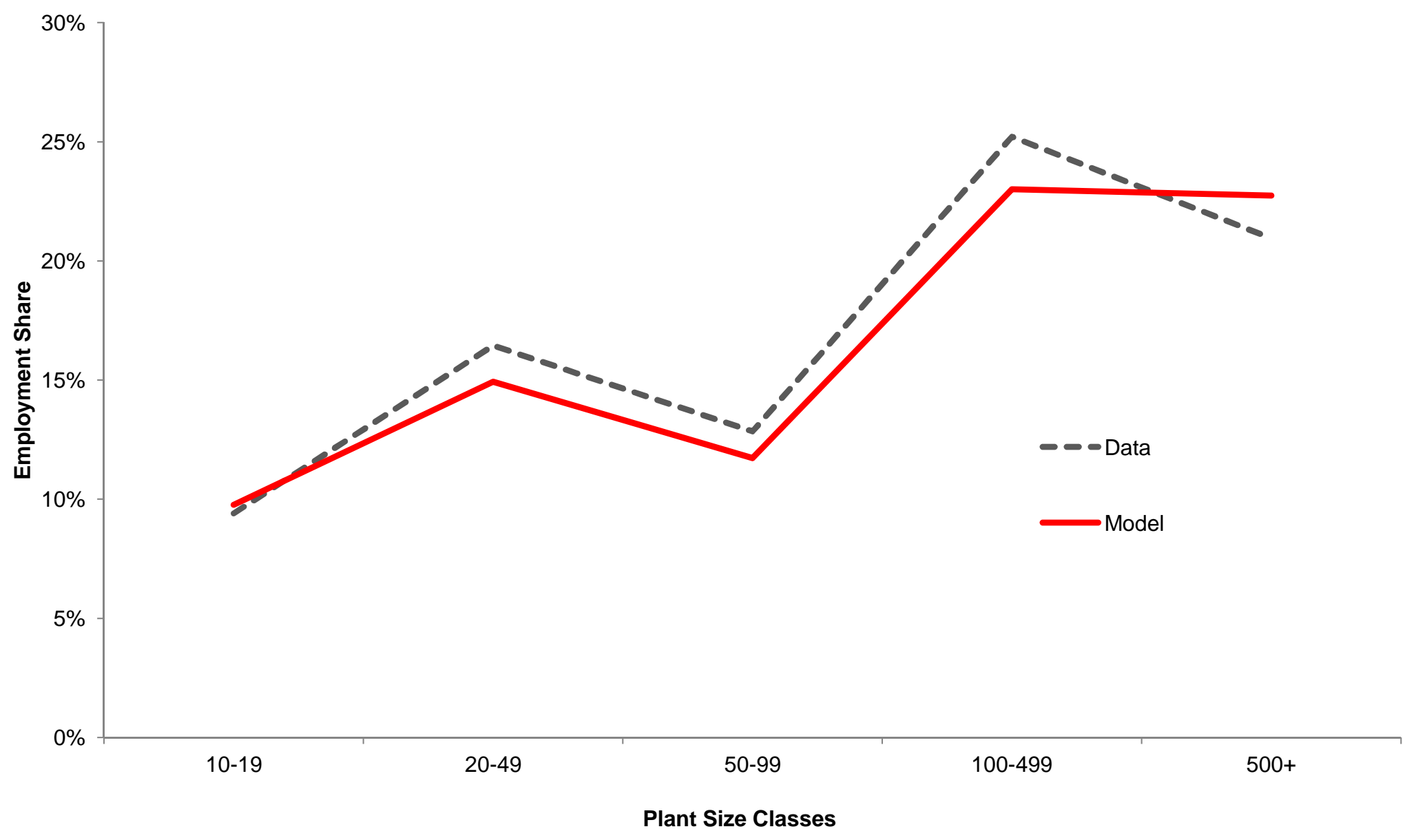


Figure 5. The Effect of Distortions on Output and Mean Size

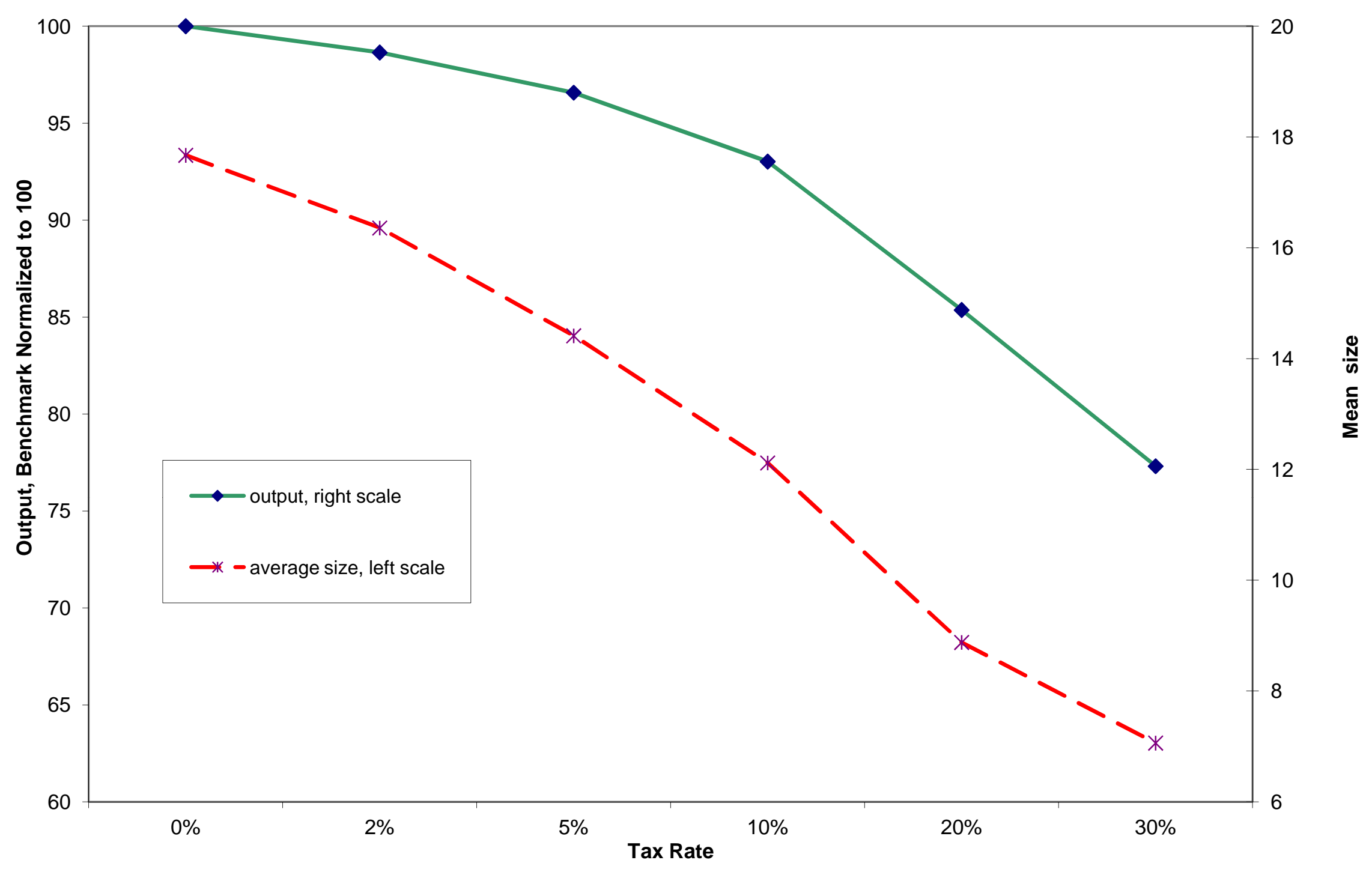


Figure 6. Investment in Skills by Age-1 Managers

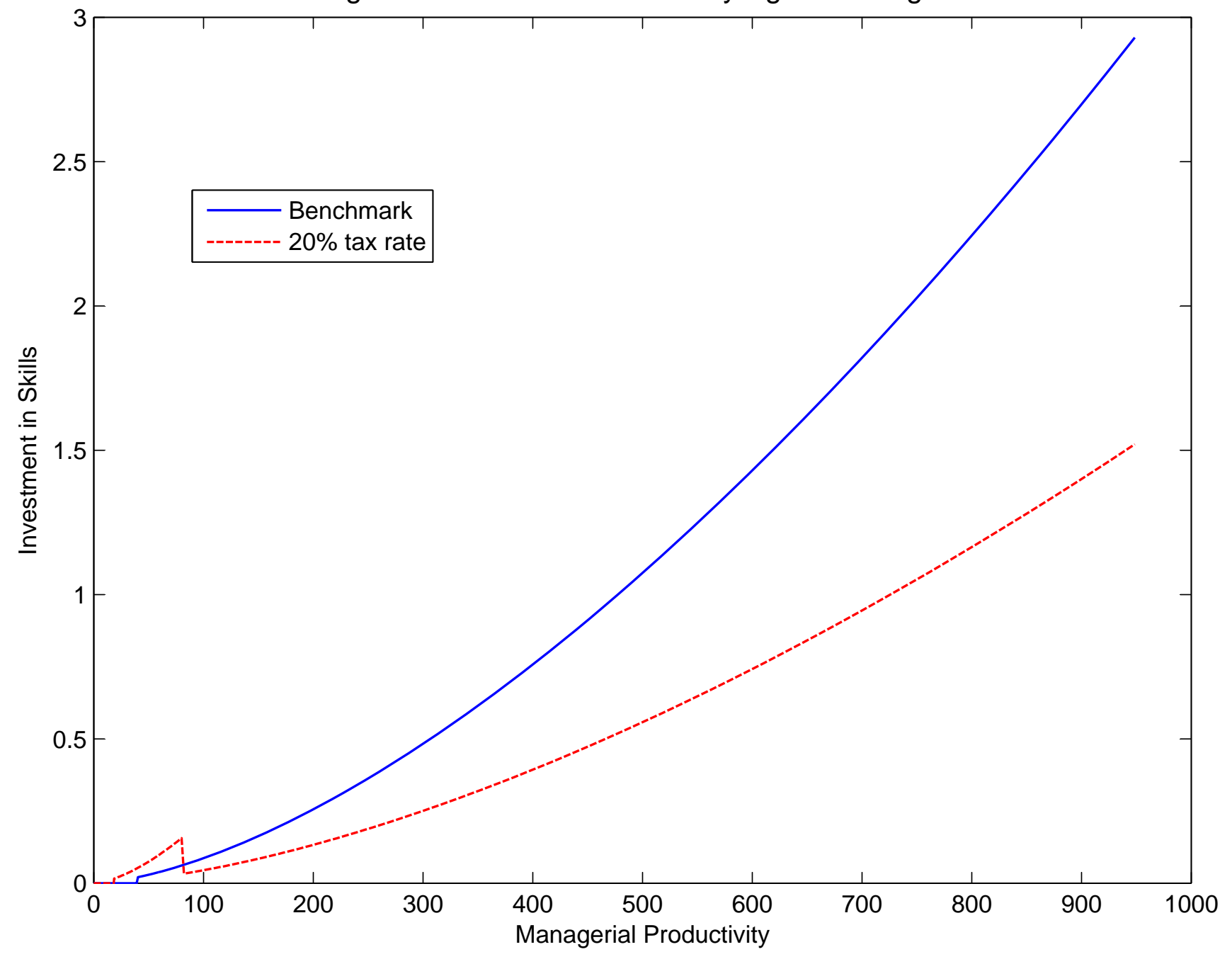


Figure 7. Amplification

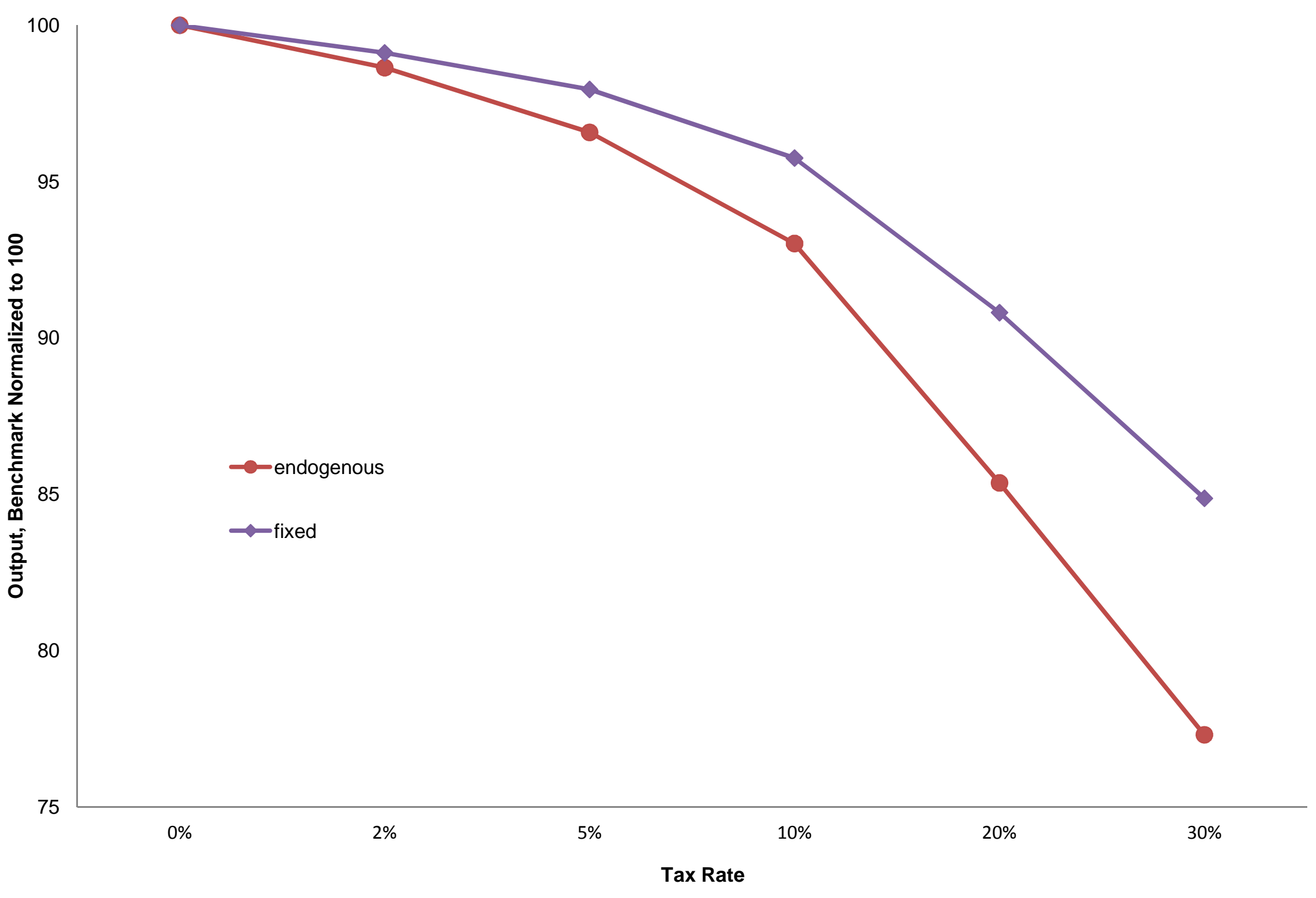

